\title{
A Novel Artificial Intelligent Approach: Comparison of Machine learning Tools and Algorithms Based on Optimization DEA Malmquist Productivity Index for Eco- efficiency Evaluation
}

\author{
Mirpouya Mirmozaffari ${ }^{1 *}$, Elham Shadkam ${ }^{2}$, Seyed Mohammad Khalili ${ }^{3}$, Kamyar Kabirifar ${ }^{4}$, Reza Yazdani $^{5}$, \\ Tayyebeh Asgari Gashteroodkhani ${ }^{6}$ \\ ${ }^{1}$ Department of Industrial Manufacturing and Systems Engineering, the University of Texas at Arlington, Arlington, TX, USA \\ ${ }^{2}$ Department of Industrial Engineering, Faculty of Engineering, Khayyam University, Mashhad, Iran \\ ${ }^{3}$ Department of Management, Ferdowsi University of Mashhad, Mashhad, Iran \\ ${ }^{4}$ Faculty of Built Environment, University of New South Wales, Sydney, Australia \\ ${ }^{5}$ Department of Management, Islamic Azad University, Chalous branch, Chalous, Iran \\ ${ }^{6}$ Department of Electrical Engineering, University of Guilan, Rasht 4199613776, Iran
}

\begin{abstract}
Purpose: Cement as one of the major components of construction activities, releases a tremendous amount of $\mathrm{CO}_{2}$ into atmosphere, resulting in adverse environmental impacts and high energy consumption. Increasing demand for $\mathrm{CO}_{2}$ consumption has urged construction companies and decision makers to consider ecological efficiency affected by $\mathrm{CO}_{2}$ consumption. Therefore, this research aims at developing a method capable of analyzing and assessing the Ecoefficiency determining factor in Iran's 22 local cement companies over 2015-2019.
\end{abstract}

Design/Methodology/Approach: This research utilizes two well-known artificial intelligence approaches, namely optimization Data Envelopment Analysis (DEA) and machine learning algorithms at the first and second steps respectively to fulfill the research aim. Meanwhile, to find the superior model, CCR model, BBC model, and additive DEA models to measure the efficiency of decision processes are used. A proportional decreasing or increasing of inputs/outputs is the main concern in measuring efficiency which neglect slacks and hence, is a critical limitation of radial models. Thus, additive model by considering desirable and undesirable outputs, as a well-known DEA nonproportional and non-radial model, are utilized to solve the problem. Additive models measure efficiency via slack variables. Considering both input-oriented and output-oriented is one of the main advantages of additive model.

Findings and Implications: After applying the proposed model, the Malmquist Productivity Index (MPI) is computed to evaluate the productivity of companies over 2015-2019. Although DEA is an appreciated method for evaluating, it fails to extract unknown information. Thus, machine learning algorithms plays an important role at this step. Association rules is used to extract hidden rules, and to introduce the three strongest rules. Finally, three data mining classification algorithms in three different tools have been applied to introduce the superior algorithm and tool. A new converting two-stage to single-stage model is proposed to obtain the eco-efficiency of the whole system. This model is proposed to fix the efficiency of a two-stage process and prevent the dependency on various weights. Converting undesirable outputs, and desirable inputs to final desirable inputs in a single-stage model to minimize inputs as well as turning desirable outputs to final desirable outputs in the single stage model to maximize outputs to have a positive effect on the efficiency of the whole process

Keywords: Artificial Intelligent; Machine learning; Optimization; Data Envelopment Analysis; Two-stage additive models; Eco-efficiency; Association rules; Classification

\footnotetext{
* Corresponding author

E-mail addresses: Mirpouya.mirmozaffari@mavs.uta.edu (M. Mirmozaffari).
} 


\section{Introduction}

The construction industry is considered as a main contributor to environmental pollution and degradation (Nematzadeh et al., 2020, Shahmansouri et al., 2020b). Climate change as one of the biggest challenges facing humankind (Shahmansouri et al., 2021) and as a direct consequence of construction activities, is happening faster than previously predicted (Yazdani et al., 2020b). According to the recent researches, world's climate is experiencing a significant increase in average annual temperatures (Mahmoudi et al., 2019a). Meanwhile, the atmospheric concentrations of some greenhouse gases (GHGs), particularly CO2, engendered by construction activities, exacerbates climate change (Kabirifar et al., 2020, Yazdani et al., 2020a).

Construction industry is the largest source of GHG emissions in the world, responsible for up to $50 \%$ of emissions (Khasreen et al., 2009). Many countries in the world are experiencing the consequences of climate change, therefore they urgently need to reduce GHGs as part of a strong global effort (Fathollahi-Fard et al., 2019). For instance, the Intergovernmental Panel on Climate Change (IPCC) has suggested that the world must cut off emissions to net zero by no later than 2050 to have a chance of limiting warming to $1.5 \mathrm{C}$. However, there is growing consensus that the adaptation efforts today are insufficient in minimizing the rate and extent of projected climatic changes.

By transitioning away from conventional construction practices to novel technologies, methods, and materials, the construction industry has considerable potential to reduce GHG emissions (Shahmansouri et al., 2020a). Although there are many researches in the construction industry have focused on assessing the industry's preparedness and capacity to adapt to climate change risks (e.g. (Hurlimann et al., 2019)), there is relatively little research in using ecofriendly materials in construction industry. The materials used in construction sector such as cement release a considerable amount of carbon dioxide (CO2) (Tekin et al., 2020). Therefore, replacing some materials with eco-friendly alternatives can help to reduce the $\mathrm{CO} 2$ emission.

Many countries are investing on developing infrastructures (Chen et al., 2019, Kabirifar and Mojtahedi, 2019), and in these projects cement is one of the most used construction materials in the world (Akbarzadeh Bengar et al., 2020, Akbarzadeh Bengar and Shahmansouri, 2020). Although PC is beneficial in many aspects, its production emits approximately $7 \%$ of the entire human-related CO2 released into the atmosphere (Metz et al., 2005, Taylor et al., 2006). Of the GHG emissions associated with cement production, around 50\% comes from the calcination (CaO formation via deriving CO2 from CaCO3), with the other 50\% from the energy used within the procedure (Yang et al., 2013, ÁvalosRendón et al., 2018). Approximately four billion tons of PC is made each year, which makes it the primary binder in the building industry (Pacheco-Torgal et al., 2012). Based on estimates, around 6 billion tons of PC will be used annually in the next four decades (Samimi et al., 2017). Therefore, developing new binders requiring less energy to produce and leading to less GHG emissions has become a necessity. Therefore, it is crucial to develop a method capable of analyzing and assessing the efficiency of ecological systems with regard to cement production in cement companies.

Searching for a novel machine learning and optimization approaches to find the most appropriate model is still an open problem (Yazdani and Ghodsi, 2017, Yazdani and Jolai, 2016, Yazdani et al., 2017a). Thus, in responding to this research gap, in current study the combination of the above-mentioned machine learning and optimization approaches/methods will be a new experiment in literature perception. DEA as one of the main concepts of the optimization method has been widely used for calculating energy and environmental efficiency and eco-efficiency since it was primarily proposed by (Charnes et al., 1978). It is a non-parametric frontier technique where the efficiency of a specific entity is calculated by its distance from the highest performance practice frontier created by the most exceptional performance entities inside the group. DEA is a general method for assessing the efficiency of ecological systems (Li et al., 2019, Mirmozaffari et al., 2020).

Data mining is world-class expertise with exceptional potential to aid the companies. The data mining methods such as classification forecast upcoming trends and performances. Data mining is a process of extracting valuable information from large amounts of data. The volume of data is growing dramatically as the data created by commonplace actions. Thus, taking out association rules from a large quantity of data in the database is interesting in numerous industries. Association rule mining has an excellent reputation in data mining. Apriori is the critical algorithm in association rule mining. Apriori algorithm is the most classical and essential algorithm for mining frequent item sets proposed by (Agarwal and Srikant, 1994). Apriori is used to find all routine item sets in each database. The 
main idea of the Apriori algorithm is to make numerous authorizations over the database. It employs an iterative method recognized as a breadth-first search (level-wise search) through the search space, where k-item sets are used to explore $(\mathrm{k}+1)$-item sets.

Recently, several open-source data mining tools and software are accessible such as the Waikato Environment for Knowledge Analysis (WEKA), Rapid miner, and Tanagra. These tools and software offer a set of approaches and algorithms that support in better evaluation of data.

The analysis of Eco-efficiency is separated into two stages. The first stage uses its inputs to produce outputs, in which outputs are consequently considered as the inputs of the second stage. The first stage is reflected as the production stage and the second stage as the pollution control stage. In current study, all the available companies' datasets are applied to three exclusive models, and their DMU's efficiency is compared to find the unfamiliar trends in cement companies. A dataset for 22 companies with one input, two intermediate products, and three outputs after converting two-stage to proposed single-stage model is used. MPI in DEA with CCR, BCC, and additive Models are applied to test and justify the alterations between companies. The use of DEA as a decision analysis tool is limitless in literature because DEA does not focus on finding a universal relationship for all unit's undervaluation in the sample. DEA authorities every group in the data to have its production function, and then it evaluates the efficiency of that single unit by comparing it to the efficiency of the other units in the dataset. After running the three MPI models in DEA SOLVER with every group in the data, data mining classification algorithms in three strong data mining tools which are WEKA, Tanagra and Rapid Miner have been applied to find the superior tool and algorithm. Many classification algorithms should be applied to analyze and classify data. These algorithms differ in their nature and performance. Thus, in order to choose the best algorithm, a comparison studies required to present the most appropriate approach to be implemented in certain domain. The rest of the paper is organized as follows:

Section 2 reviews the literature linked to the calculation of Eco-efficiency, energy use efficiency, and specifies the prospective role of the current study. Section 3 presents a clarification of the data set description and data sources. Section 4 discusses the nine parts of the research methodology (part1: CCR, part2; BCC part3: additive models, part4: radial and non-radial models part5:Proposed model, part6: MPI, part7: Apriori algorithm in association rules, part8: Three strong classification algorithms in machine learning and the final calculation of accuracy, part9: Assessment process of combining DEA and data mining. Section 5 presents an evaluation and result of MPI and data mining algorithms respectively followed by a discussion and conclusion of the experimental consequences in Section 6 and 7 correspondingly.

\section{Background and literature review}

In this section, first, the existing studies relevant to this paper are reviewed, then research gaps and the main contributions of this study are discussed.

\subsection{MPI and non-radial model based on energy, environmental and industrial ecological efficiency}

Graham (2009) is the first to apply an ecologically complex DEA Malmquist productivity index to find how ecological facilities effect measured productivity in the long run. The capability to include ecological influences lacking price data into MPI makes the index attractive for This research. Ødegaard and Roos (2014) combine MPI and bootstrap DEA to examine the influence of labor quality attributes in the direction of firm productivity. Finally, (Arabi et al., 2014) present a novel SBM for Malmquist-Lueberger (ML) Index, and in the next year, (Arabi et al., 2015) proposed the same model integrating undesirable outputs. Meanwhile, in many production procedures, large amounts of undesirable outputs are produced. The side effects of undesirable outputs on efficiency cannot be handled by standard MPI to measure productivity change over time. Consequently, A DEA model and an algorithm were introduced which can eliminate a common problem. This model includes the best way among all other guidelines to increase desirable output and decrease undesirable outputs simultaneously. Finally, a simple example used to demonstrate the novel algorithm, and the actual application of steam power plants is applied to display the applicability of the projected model. In the next year, (Emrouznejad and Yang, 2016a, Emrouznejad and Yang, 2016b) developed the previous model given its summing of slacks of good and bad outputs as the objective function of their models. Ghulam and Jaffry (2015) applied the MPI to study productivity in cement companies in Pakistan. Results indicated that privatization and lower degrees of organizational involvement in such companies had an advanced effect on the company's productivity. This 
development related to the durability of political environments, economic status improvement, and an increasing uselessness. Zhang et al. (2015) using the MPI to assess the performance of events containing CO2 in the transportation industry in China. The investigation took place in several periods, showing that the performance of the Chinese transportation industry had fallen by 32.8 percentage. This declining performance was attributed to a low level of technology in the field Applying the DEA Slack Based Model (SBM) under the reflection of constant returns to scale and variable return to scale technologies, a composite index is considered from the efficiency scores of each model. These models reflect both desirable and undesirable outputs.

\subsection{Eco-efficiency evaluation with desirable or undesirable inputs and outputs}

Increasing concerns around the topic of energy safety and global warming, the problem of energy efficiency has gained significant attention from researchers. According to the International Energy Agency (IEA) energy efficiency is a way of handling and restricting the growth in energy consumption. Something is more energy-efficient than other methods if it distributes more services for the same energy input or the services for less energy input.

The number of DEA applications regarding pollutant services, as well as undesired outputs, is noteworthy. Separating ecological and technical efficiencies for power plants, Korhonen and Luptacik (2004) suggested an approach. They consider pollutants as the inputs in order to increase desirable outputs and decrease pollutants and inputs. Gomes and Lins utilized Zero Sum Gains DEA to calculate carbon dioxide emissions. According to technical aspects, Yang and Pollitt (2010) have considered several impossibilities features as undesirable outputs. In an experimental study, Zhang et al. (2008) used DEA to assess the eco-efficiency of gross domestic products in China. Liu et al. (2010) came across an approach to combine desirable and undesirable inputs and outputs. Chu et al. (2019) emphasized on the eco-efficiency study of Chinese provincial-level regions, concerning each region as a two-stage network structure. The first stage is reflected in the production system, and the second stage is considered as the pollution control system. Regarding the pollution emissions as intermediate products, a two-stage DEA model is suggested to attain the eco-efficiency of the entire two-stage structure. Khalili-Damghani and Shahmir (2015) have considered emissions as an undesirable output in the efficiency assessment of electric power production and distribution procedure. Oggioni et al(2011) .used DEA to evaluate energy as an input producing both desirable outputs (goods) and undesirable outputs (CO2 emissions). The exclusion of undesirable output does not appear to deliver a broad scale of the production procedure. Consequently, Zhou and Ang (2008) assess energy use efficiency in a combined production context of both desirable and undesirable output.

To comprehend whether this eco-efficiency is attributable to a sensible consumption of inputs or an actual CO2 lessening as a result of the ecological rule, they evaluate the circumstances where CO2 emissions can either be reflected as an input or as an undesirable output. Practical effects display that countries, where cement industries spend in scientifically innovative kilns and adopt substitute fuels and raw materials in their manufacturing processes, are ecoefficient. Environment et al. (2018) proposed two essential approaches, which have a positive influence in substantial additional reductions in $\mathrm{CO} 2$ emissions and increased the use of the low-CO2 supplement, including the more efficient use of cement clinker. This efficient use contributes a relative advantage to developed countries, such as India and China, which are encouraged to renovate their production processes. In terms of CO2 emissions, DEA, and ecoefficiency, some outstanding recent studies can be addressed in the literature (Grigoroudis and Petridis, 2019, Wang et al., 2011, Almutairi and Elhedhli, 2014, Bi et al., 2014, Zeng et al., 2016a, Li and Lin, 2016, Jiang et al., 2016, Zeng and Chen, 2016, Zeng et al., 2016b, Mahmoudi et al., 2019b, Jin et al., 2018, Khoshroo et al., 2018, Arabi et al., 2017, Boyd and Pang, 2000, Wei et al., 2007, Azadeh et al., 2007, Angulo-Meza et al., 2019, Balitskiy et al., 2016, Bian et al., 2016, Moya et al., 2016, Mirmozaffari, 2019, Lee and Park, 2017, Yu et al., 2014).

\subsection{Machine learning algorithms in energy consumption}

Making effective decisions is crucial in any field (Khalili et al., 2016, Aghapour et al., 2019). Innovative computational methods particularly machine learning and soft computing techniques have the potential to tackle a wide range of challenging problems (Yazdani et al., 2016, Yazdani et al., 2017b, Yazdani et al., 2018, Yazdani and Jolai, 2013, Shahmansouri et al., 2019, Golilarz et al., 2019, Golilarz et al., 2020), therefore they have widely been applied in different fields in recent years (Yazdani et al., 2019, Azadeh et al., 2016). Yu et al. (2014) addressed the regional distribution of carbon emission reduction goals in China based on the constituent part swarm optimization algorithm, fuzzy c-means clustering algorithm, and Shapley decomposition approach. Consequently, they clustered all regions into four classes 
according to the relevant carbon emission features and decided that more carbon emission reduction quantity would be assigned to regions with large total emissions and high emission concentration. Emrouznejad et al. (2019) considered the same problem of this article, despite the fact that they applied an inverse DEA method and ignored the competitive and supportive relations between various sub-level trades and regions. Qing et al. (2012) extracted building energy consumption data by DBSCAN clustering and decision tree-based classification methods. Despite its capability to intensely comprehend the outline of energy consumption in constructions, the algorithm is too intricate to be appropriate for the rapid processing of data in the energy consumption monitoring platform.

\subsection{Three strong data mining tools (WEKA, Rapid miner, and TANAGRA)}

In this part, three strong data mining tools are introduced (Naik and Samant, 2016):

- WEKA is an extensively implemented tool for machine learning that was initially established at the University of Waikato in New Zealand. It includes many groups of advanced machine learning algorithms written in Java. This tool covers tools for regression, classification, clustering, association rules, visualization, and data pre-processing.

- Rapid miner (RM) is a user collaborative tool for machine learning procedures. It is written in Java. It shows an integrated method to design even very intricate problems - an integrated operative perception which lets the design of compound nested operator chains for a large number of learning problems. RM applied XML to define the operative trees modeling knowledge discovery $(\mathrm{KD})$ procedures. It has flexible workers for data input and output in diverse file formats. It covers more than 100 learning systems for classification, regression and clustering algorithms.

- Tanagra is a free suite of machine learning software to study and theoretical methods established by Rakotomalala (2005) at the Lumière University, France. It provides numerous standard machine learning approaches such as: Visualization, Descriptive statistics, Instance selection, feature selection, feature construction, regression, factor analysis, clustering, classification and association rule learning. Tanagra supports an appropriate cooperation among the statistical methods (e.g. parametric and nonparametric statistical tests), the multivariate analysis approaches (e.g. factor analysis, correspondence analysis, cluster analysis, regression) and the machine learning techniques (e.g. neural network, support vector machine, decision trees, random forest).

\subsection{Research gap analysis and contributions}

DEA measure of energy use efficiency has two main benefits as compared to the old-style meaning, "the percentage of energy services to energy input." At the initial step, DEA provides somewhere to stay several inputs (energy and noenergy inputs) and several outputs (desirable and undesirable) in the production progression. Next, DEA can also put up the purposes of DMUs in evaluating energy use efficiency. However, far too little attention has been paid to developing an efficient solution method to cope with DEA and data mining associated with finding the superior model, algorithm and DMU. In conclusion, main contributions of this study can be summarized as follows:

- This research aims to study a comprehensive comparison of several efficiencies delivers insight into the firm's efficiency based on machine learning combined with innovative optimization models for Eco-efficiency Evaluation. This comparison is of considerable significance to cement companies' practitioners who desire to assess productivity and efficiency at a proper step of its progression.

- An exclusive, effective and easy to implement converting two-stage to single stage models in MPI are applied with DEA SOLVER, which eventually results in comparing several efficient and inefficient DMUs. This model is proposed to fix the efficiency of a two-stage process and prevent the dependency on various weights. In fact, by converting two-stage to single proposed stage, desirable and undesirable inputs and output can be evaluated with simple CCR, BCC and additive suggested model.

- After applying the abovementioned optimization part, best machine learning tool and algorithm are introduced. DEA inputs and outputs as potential attributes for data mining classification algorithms in WEKA, Tanagra and Rapid miner are considered. In addition, data play the role of instances and finally efficient DMUs are applied for class yes and inefficient DMUs for class no.

- After using the aforementioned novel combined optimization and machine learning approaches, the superior 
model, company, algorithm, and tool will be introduced. Thus, it can be beneficial for managers to remove unrelated data and conduct more effective processes.

\section{Dataset description}

The standard data set, collected in this study covers five years (2015-2019), which is collected from 22 cement companies. Consequently, the single input of the first stage, two intermediate elements, and three outputs of the second stage for the first company, which is 2015 to 2019, are presented in Table 1.

Table 1. The inputs, intermediate elements, and outputs for the 1ST DMUs

\begin{tabular}{ccccccc}
\hline Period & $\begin{array}{c}\text { Input } \\
\text { (Energy } \\
\text { Consumption } \\
(1000 T C E))\end{array}$ & $\begin{array}{c}\text { Intermediate } \\
\text { Elements } \\
\text { (Cement }\end{array}$ & $\begin{array}{c}\text { Intermediate } \\
\text { Elements } \\
\text { (Pollution Control } \\
\text { Investment }\end{array}$ & $\begin{array}{c}\text { Output } \\
\text { (Waste } \\
\text { Material } \\
\text { Removed } \\
(1 \text { ton) })\end{array}$ & $\begin{array}{c}\text { Output } \\
\text { (Waste gas } \\
\text { Removed } \\
(1 \text { ton) })\end{array}$ & $\begin{array}{c}\text { Output } \\
\text { (Solid waste } \\
\text { Removed } \\
(1 \text { ton) })\end{array}$ \\
\hline 2015 & 1063116 & 730865 & 800000 IRR) & 107237 & 28.92 & 22421.24 \\
2016 & 1425490 & 1216569 & 143427 & 289883 & 19.24 & 543.25 \\
2017 & 1965650 & 1560395 & 153450 & 254899 & 25.93 & 2341.23 \\
2018 & 2539977 & 1861560 & 134566 & 264522 & 28.93 & 1451.22 \\
2019 & 2805942 & 2008740 & 144000 & 381952 & 6.54 & 8739.98 \\
\hline
\end{tabular}

Energy consumptions in the companies are the only input in the first stage. Cement production (outputs of the first stage) and pollution control investments (input of the second stage) are two intermediate elements. Waste material removed in companies is the single output of the second stage.

\section{Research methodology}

The objective of this study after converting two-stage to a single-stage is to compare companies' efficiency effectively. Using a comparative DEA with window analysis methodology and clustering algorithms in data mining were established to determine the features of cement companies in terms of some DMUs and algorithms. Finally, the entire progression can be divided into five steps, as follows:

\subsection{CCR Model:}

The CCR models show a constant return to scale (CRS), which means that relative progress in all inputs is equal to the increase in outputs. The efficiency of an assumed DMU is calculated based on the CCRIO model as follows:

$\operatorname{Min} \theta$

St.

$\sum_{j=1}^{n} \lambda_{j} x_{i j} \leq \theta_{p} \quad, i=1, \ldots \ldots, m$

Eq. 1

$$
\sum_{j=1}^{n} \lambda_{j} y_{r j} \geq y_{r p} \quad, r=1, \ldots \ldots ., s
$$

$\lambda_{j} \geq 0 \quad, j=1, \ldots, n$

Where $\theta p$ specifies the technical efficiency score of units DMU, $\lambda \mathrm{j}$ indicates the dual variables that categorize the benchmarks for inefficient parts. If $\theta$ pis equal to one, then the DMU shows a technically efficient unit. It is on the efficiency frontier, which is collected from the set of efficient units. DEA calculates the efficiency of each observation based on the frontier that covers all the views. Inefficient DMUs can be improved (moved to the efficient frontier) with strategic directions for precision, which are the points along the frontier. The distance to the efficiency frontier distributes an amount of efficiency.

\subsection{BCC Model:}


The BCC model changed the Constant Return to Scale (CRS) impression to Variable Return to Scale (VRS). The DMU controls under VRS, and it is observed that growth in inputs does not result in a relative change in the outputs. The BCC model divides Technical Efficiency (TE) based on the CCR model into two parts:

- Pure Technical Efficiency (PTE): PTE provides the effect of scale size by just connecting a DMU to a unit of comparable scale and procedures on how a DMU develops its bases under the outer region.

- Scale Efficiency (SE): SE, shows how the scale size has positive or negative influences on efficiency. If after using both CRS and VRS models on similar data, there is a change in the two technical efficiencies, and based on these tags, DMU has a scaling efficiency and can be designed by:

$S E=T E / P T E$

The $\mathrm{BCC}_{\mathrm{IO}}$ is represented as follows:

$\operatorname{Min} \theta$

St.

$\sum_{j=1}^{n} \lambda_{j} x_{i j} \leq \theta_{p} \quad, i=1, \ldots \ldots, m$

$\sum_{j=1}^{n} \lambda_{j} y_{r j} \geq y_{r p} \quad, r=1, \ldots \ldots, s$

Eq. 3

$\sum_{j=1}^{n} \lambda_{j}=1$

$\lambda_{j} \geq 0 \quad, j=1, \ldots, n$

\subsection{Additive Model (AM)}

This model reflects the input surplus and the output shortage concurrently with incoming at a point on the efficient frontier. In addition, as a non-radial model, when dealing with undesirable outputs, slacks in undesirable outputs are accounted for the efficiency measure. In mathematical terms the Constant Return to Scale (CRS) for AM model or AMCRS is given as:

$$
\operatorname{MinZ}=\sum_{i=1}^{m} S_{i}^{-}+\sum_{r=1}^{s} S_{r}^{+}
$$

St.

$$
\begin{array}{ll}
\sum_{j=1}^{n} \lambda_{j} x_{i j}+S_{i}^{-}=x_{i} & , i=1, \ldots \ldots ., m \\
\sum_{j=1}^{n} \lambda_{j} y_{r j}-S_{r}^{+}=y_{r} & , r=1, \ldots \ldots ., S \\
\lambda_{j}, S_{r}^{+}, S_{i}^{-} \geq 0 \quad, j=1, \ldots, n &
\end{array}
$$

Eq. 4

After adding the following constrain to the abovementioned AM-CRS or relation number

$$
\sum_{j=1}^{n} \lambda_{j}=1
$$

We can convert CRS to Variable Return to Scale (VRS) model. This is exactly like the converting CCR to BCC model. In technical relations, the AM-VRS model is given as:

$$
\operatorname{MinZ}=\sum_{i=1}^{m} S_{i}^{-}+\sum_{r=1}^{s} S_{r}^{+}
$$


St.

$$
\begin{array}{ll}
\sum_{j=1}^{n} \lambda_{j} x_{i j}+S_{i}^{-}=x_{i} & , i=1, \ldots \ldots ., m \\
\sum_{j=1}^{n} \lambda_{j} y_{r j}-S_{r}^{+}=y_{r} & , r=1, \ldots \ldots ., S \\
\sum_{j=1}^{n} \lambda_{j}=1 & , j=1, \ldots, n
\end{array}
$$

\subsection{Radial and non-radial Models}

The main AM objective, as a radial model, is to achieve the highest value of the input and output slacks in the given DMUs. DEA measures the efficiency of each reflection relative to the frontier that covers all the explanations. Inefficient DMUs can be value-added (moved to the efficient frontier) with proposed advice for development, which are the points along the frontier. The distance to the efficiency frontier delivers a measure of efficiency. To clarify more, Figure 1 shows the main differences between radial and no-radial models with two inputs and one output in Farrell efficiency border.

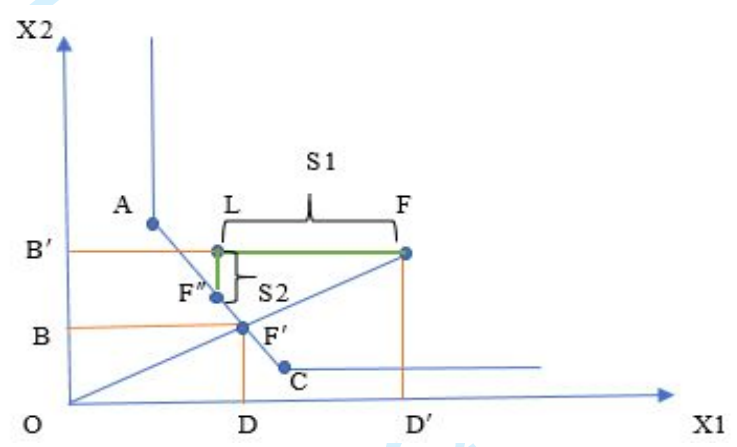

Fig. 1. Radial and non-radial models with two inputs and one output

In Figure 1, the efficient frontier represented by the solid line passes through $\mathrm{A}, \mathrm{F}^{\prime}, \mathrm{F}^{\prime \prime}, \mathrm{C}$ and no other points. Therefore, for $F^{\prime}, F^{\prime \prime}$,in order to be efficient DMUs, it is needed to bring each DMU onto the efficient frontier. Thus, we want to bring F DMU onto efficient frontier based on radial models' rule. The value of $\theta^{*}$ which is available in the following equation should be applied to $F$ inputs and finally will bring it to $\mathrm{F}^{\prime}$ (onto AC efficient frontier).

$$
\theta^{*}=\frac{O D}{O \mathrm{D}^{\prime}}=\frac{O B}{O B^{\prime}}
$$

Based on the above calculation, $\mathrm{F}^{\prime}$ represents radial efficient DMU. In fact, in radial models, the reducing amounts of inputs and outputs should be the same. On the other hand, in non-radial models, it is not necessary to apply the same reducing amounts for inputs or outputs and this is one of the advantages of radial models. For non-radial or AM models, based on figure 1, the following two separate steps should be considered:

1. Reducing the first input by $S_{1}{ }^{-}=F L$ at the first step

2. Reducing the second input by $S_{2}{ }^{-}=\mathrm{LF}^{\prime \prime}$ at the second step

Based on the above calculation, $F^{\prime \prime}$ shows non-radial efficient DMU. The major concern of input (output)-oriented models focuses on the input (output)-side efficiency, and output (input)-side is a minor subject in measuring efficiency. In addition, only the non-radial models can capture the whole features of efficiency. Thus, in order to get the whole advantages of efficiency, AM model has been used in this study. 


\subsection{Proposed model}

\subsubsection{A new approach in DEA two-stage model}

Many papers have proposed a novel two-stage model in DEA (Chen et al., 2009a, Chen et al., 2009b, Kao and Hwang, 2008, Lotfi et al., 2012). . Decreasing pollutant material investment, as well as energy consumption (inputs of the single proposed model) and increasing waste material removed as well as cement production (outputs of the unique proposed model) have a positive influence on profits, and efficiency of cement companies. Figure 1 explains the propose a novel converting two-stage to single standard model with the following items:

- $X_{i j}(\mathrm{i}=1, \ldots, \mathrm{m})$ : Energy consumption or input of the first stage

- $\quad Y_{r j}(\mathrm{r}=1, \ldots, \mathrm{s})$ : Wastewater removed or desirable output of the second stage

- $\quad E_{t j}(\mathrm{t}=1, \ldots, \mathrm{v})$ : Waste gas removed or desirable output of the second stage

- $\quad F_{z j}(\mathrm{z}=1, \ldots, \mathrm{q})$ : Solid waste removed or desirable output of the second stage

- $\quad M_{h j}(\mathrm{~h}=1, \ldots, \mathrm{d})$ : Cement production or desirable output of the first stage

- $\quad N_{c j}(\mathrm{c}=1, \ldots, \mathrm{k})$ : Pollution control investment or input of the second st age

- $\quad D M U_{j}(\mathrm{j}=1, \ldots, \mathrm{n})$ : Decision Making Units

Figure 2 shows the structure of the proposed model:

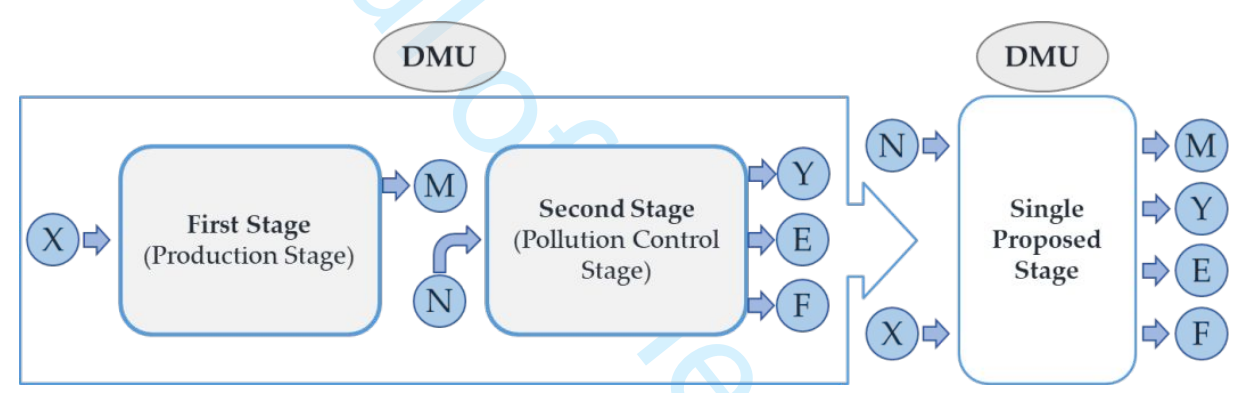

Fig. 2. Conversion of the two-stage model to the one-stage mode

The two-stage model is considered as single-stage, where the intermediate elements depending on being desirable or undesirable, are considered as part of final desirable outputs or desirable inputs in the proposed single-stage model. Description of dimensionless parameters in nomenclature for primal and dual proposed model are provided in Table 2:

Table2. Explanation of dimensionless parameters in nomenclature for primal and dual proposed model

\begin{tabular}{cl}
\hline $\begin{array}{c}\text { Dimensionless } \\
\text { parameters }\end{array}$ & Units \\
\hline$D M U_{j}$ & Decision making units \\
$S_{i}^{-}\left(S_{1}^{-}, \ldots, S_{m}^{-}\right)$ & Vector of input (Energy consumption) surplus (consumption slack) \\
$S_{r}^{+}\left(S_{1}^{+}, \ldots, S_{s}^{+}\right)$ & Vector of output (Wastewater removed) shortfall (production slack) \\
$S_{h}^{+}\left(S_{1}^{+}, \ldots, S_{d}^{+}\right)$ & Vector of output (Cement production) shortfall (production slack) \\
$S_{t}^{+}\left(S_{1}^{+}, \ldots, S_{v}^{+}\right)$ & Vector of output (Waste gas removed) shortfall (production slack) \\
$S_{z}^{+}\left(S_{1}^{+}, \ldots, S_{q}^{+}\right)$ & Vector of output (Solid waste removed) shortfall (production slack) \\
$S_{c}^{-}\left(S_{1}^{-}, \ldots, S_{k}^{-}\right)$ & Vector of input (Pollution control investment) surplus (consumption slack) \\
$\lambda_{j}$ & Non-negative scalar (dual variables that categorize the benchmarks for inefficient parts) \\
$X_{i j}$ & $m^{t h}$ input (Energy consumption) for $n^{t h}$ DMU \\
$Y_{r j}$ & $s^{t h}$ output (Wastewater removed) for $n^{t h} \mathrm{DMU}$ \\
$M_{h j}$ & $d^{t h}$ output (Cement production) for $n^{\text {th }} \mathrm{DMU}$ \\
$E_{t j}$ & $v^{t h}$ output (Waste gas removed) for $n^{t h} \mathrm{DMU}$ \\
$F_{z j}$ & $q^{t h}$ output (Solid waste removed) for $n^{t h} \mathrm{DMU}$ \\
$N_{c j}$ & $k^{t h}$ input (Pollution control investment) for $n^{t h} \mathrm{DMU}$ \\
$w$ & Free of sign for variable return to scale \\
\hline
\end{tabular}




\begin{tabular}{|c|c|}
\hline$j$ & $n^{t h} \mathrm{DMU}$ \\
\hline$n$ & DMU observation \\
\hline$m$ & Input (Energy consumption) observation \\
\hline$s$ & Output (Wastewater removed) observation \\
\hline$d$ & Output (Cement production) observation \\
\hline$v$ & Output (Waste gas removed) observation \\
\hline$q$ & Output (Solid waste removed) observation \\
\hline$k$ & Input (Pollution control investment) observation \\
\hline$i$ & $m^{\text {th }}$ input (Energy consumption) \\
\hline$r$ & $s^{\text {th }}$ output (Wastewater removed) \\
\hline$h$ & $d^{\text {th }}$ output (Cement production) \\
\hline$t$ & $v^{\text {th }}$ output (Waste gas removed) \\
\hline$z$ & $q^{t h}$ output (Solid waste removed) \\
\hline$c$ & $k^{t h}$ input (Pollution control investment) \\
\hline$u_{r}$ & Weight assigned to output $\mathrm{r}$ (Wastewater removed) \\
\hline$l_{h}$ & Weight assigned to output $\mathrm{h}$ (Cement production) \\
\hline$b_{t}$ & Weight assigned to output $\mathrm{t}$ (Waste gas removed) \\
\hline$a_{z}$ & Weight assigned to output z (Solid waste removed) \\
\hline$v_{i}$ & Weight assigned to input i (Energy consumption) \\
\hline$g_{c}$ & Weight assigned to input c (Pollution control investment) \\
\hline$\phi$ & Scalar and real linear-variable representing the value of efficiency score \\
\hline$\theta$ & Scalar and real dual-variable representing the value of efficiency score \\
\hline$\theta_{p}$ & Free of sign dual scalar for $p^{\text {th }} \mathrm{DMU}$ \\
\hline$X_{i p}$ & $m^{\text {th }}$ dual input (Energy consumption) for $p^{\text {th }} \mathrm{DMU}$ \\
\hline$Y_{r p}$ & $s^{\text {th }}$ dual output (Wastewater removed) for $p^{\text {th }} \mathrm{DMU}$ \\
\hline$M_{h p}$ & $d^{\text {th }}$ dual output (Cement production) for $p^{\text {th }} \mathrm{DMU}$ \\
\hline$E_{t p}$ & $v^{\text {th }}$ dual output (Waste gas removed) for $p^{\text {th }} \mathrm{DMU}$ \\
\hline$F_{z p}$ & $q^{\text {th }}$ dual output (Solid waste removed) for $p^{\text {th }} \mathrm{DMU}$ \\
\hline$N_{c p}$ & $k^{\text {th }}$ dual input (Pollution control investment) for $p^{\text {th }} \mathrm{DMU}$ \\
\hline
\end{tabular}

Finally, in a more detailed discussion, $C C R_{I O}(C C R$ Input Oriented $), B C C_{I O}(B B C$ Input Oriented $)$ and $A M-V R S$ for primal and dual in single stage proposed model are widely discussed below:

\subsubsection{Primal model in $C C R_{I O}$ :}

$$
\begin{aligned}
& \operatorname{Max} \phi=\sum_{r=1}^{s} Y_{r} u_{r}+\sum_{h=1}^{d} M_{h} l_{h}+\sum_{t=1}^{v} E_{t} b_{t}+\sum_{z=1}^{q} F_{z} a_{z} \\
& \sum_{i=1}^{S t .} X_{i} v_{i}+\sum_{c=1}^{K} N_{c} g_{c}=1 \\
& \sum_{r=1}^{s} Y_{r} u_{r}+\sum_{h=1}^{d} M_{h} l_{h}+\sum_{t=1}^{v} E_{t} b_{t}+\sum_{z=1}^{q} F_{z} a_{z}-\sum_{i=1}^{m} X_{i} v_{i}-\sum_{c=1}^{K} N_{c} g_{c} \leq 0 \\
& u_{r}, l_{h}, v_{i}, g_{c}, b_{t}, a_{z} \geq 0, j=1, \ldots, n
\end{aligned}
$$

\subsubsection{Primal model in $B C C_{I O}$ :}

$$
\begin{aligned}
& \operatorname{Max} \phi=\sum_{r=1}^{s} Y_{r} u_{r}+\sum_{h=1}^{d} M_{h} l_{h}+\sum_{t=1}^{v} E_{t} b_{t}+\sum_{z=1}^{q} F_{z} a_{z}+w \\
& \sum_{i=1}^{S t .} X_{i} v_{i}+\sum_{c=1}^{K} N_{c} g_{c}=1 \\
& \sum_{r=1}^{s} Y_{r} u_{r}+\sum_{h=1}^{d} M_{h} l_{h}+\sum_{t=1}^{v} E_{t} b_{t}+\sum_{z=1}^{q} F_{z} a_{z}-\sum_{i=1}^{m} X_{i} v_{i}-\sum_{c=1}^{K} N_{c} g_{c}+w \leq 0 \\
& u_{r}, l_{h}, v_{i}, g_{c}, b_{t}, a_{z} \geq 0, j=1, \ldots, n
\end{aligned}
$$

\subsubsection{Primal proposed model in $A M-V R S$ :}




$$
\begin{aligned}
& \operatorname{Min} \phi=-\sum_{i=1}^{m} S_{i}^{-}-\sum_{c=1}^{k} S_{c}^{-}-\sum_{r=1}^{S} S_{r}^{+}-\sum_{h=1}^{d} S_{h}^{+}-\sum_{t=1}^{v} S_{t}^{+}-\sum_{z=1}^{q} S_{z}^{+} \\
& \sum_{j=1}^{n t .} \lambda_{j} X_{i j}+S_{i}^{-}=X_{i} \quad, i=1, \ldots, m \\
& \sum_{j=1}^{n} \lambda_{j} N_{c j}+S_{c}^{-}=N_{c} \quad, c=1, \ldots, k \\
& \sum_{j=1}^{n} \lambda_{j} Y_{r j}-S_{r}^{+}=Y_{r} \quad, r=1, \ldots, S \\
& \sum_{j=1}^{n} \lambda_{j} M_{h j}-S_{h}^{+}=M_{h} \quad, h=1, \ldots, d \\
& \sum_{j=1}^{n} \lambda_{j} E_{t j}-S_{t}^{+}=E_{t} \quad, t=1, \ldots, v \\
& \sum_{j=1}^{n} \lambda_{j} F_{z j}-S_{z}^{+}=F_{z} \\
& \sum_{j=1}^{m} \lambda_{j}=1 \\
& \lambda_{j}, S_{i}^{-}, S_{c}^{-}, S_{r}^{+}, S_{h}^{+}, S_{t}^{+}, S_{z}^{+} \geq 0, j=1, \ldots, q
\end{aligned}
$$

\subsubsection{Dual proposed model in $C C R_{I O}$ :}

$\operatorname{Min} \theta$

St.

$$
\begin{aligned}
& \sum_{r=1}^{s} Y_{r} u_{r}+\sum_{h=1}^{d} M_{h} l_{h}+\sum_{t=1}^{v} E_{t} b_{t}+\sum_{z=1}^{q} F_{z} a_{z}-\sum_{i=1}^{m} X_{i} v_{i}-\sum_{c=1}^{K} N_{c} g_{c} \leq 0, j=1, \ldots, n \\
& \sum_{j=1}^{n} \lambda_{j} X_{i j} \leq \theta_{p} X_{i p} \\
& \sum_{j=1}^{n} \lambda_{j} N_{c j} \leq \theta_{p} N_{c p} \\
& \sum_{j=1}^{n} \lambda_{j} Y_{r j} \geq Y_{r p} \\
& \sum_{j=1}^{n} \lambda_{j} M_{h j} \geq M_{h p} \\
& \sum_{j=1}^{n} \lambda_{j} E_{t j} \geq E_{t p} \\
& \sum_{j=1}^{n} \lambda_{j} F_{z j} \geq F_{z p} \\
& \lambda_{j} \geq 0 \quad \theta_{p} \text { free }
\end{aligned}
$$

\subsubsection{Dual proposed model in $B C C_{I O}$ :}

$\operatorname{Min} \theta$

St.

$$
\begin{aligned}
& \sum_{r=1}^{s} Y_{r} u_{r}+\sum_{h=1}^{d} M_{h} l_{h}+\sum_{t=1}^{v} E_{t} b_{t}+\sum_{z=1}^{q} F_{z} a_{z}-\sum_{i=1}^{m} X_{i} v_{i}-\sum_{c=1}^{K} N_{c} g_{c}+w \leq 0 \quad, j=1, \ldots, n \\
& \sum_{j=1}^{n} \lambda_{j} X_{i j} \leq \theta_{p} X_{i p} \\
& \sum_{j=1}^{n} \lambda_{j} N_{c j} \leq \theta_{p} N_{c p} \\
& \sum_{j=1}^{n} \lambda_{j} Y_{r j} \geq Y_{r p} \\
& \sum_{j=1}^{n} \lambda_{j} M_{h j} \geq M_{h p}
\end{aligned}
$$




$$
\begin{aligned}
& \sum_{j=1}^{n} \lambda_{j} E_{t j} \geq E_{t p} \\
& \sum_{j=1}^{n} \lambda_{j} F_{z j} \geq F_{z p} \\
& \sum_{j=1}^{n} \lambda_{j}=1 \\
& \lambda_{j} \geq 0 \quad \theta_{p} \text { free }
\end{aligned}
$$

\subsubsection{Dual proposed model in $A M-V R S$ :}

$$
\begin{aligned}
& \operatorname{Max} \theta \sum_{r=1}^{s} Y_{r} u_{r}+\sum_{h=1}^{d} M_{h} l_{h}+\sum_{t=1}^{v} E_{t} b_{t}+\sum_{z=1}^{q} F_{z} a_{z}-\sum_{i=1}^{m} X_{i} v_{i}-\sum_{c=1}^{K} N_{c} g_{c}, j=1, \ldots, n \\
& \text { St. } \\
& \sum_{r=1}^{s} Y_{r} u_{r}+\sum_{h=1}^{d} M_{h} l_{h}+\sum_{t=1}^{v} E_{t} b_{t}+\sum_{z=1}^{q} F_{z} a_{z}-\sum_{i=1}^{m} X_{i} v_{i}-\sum_{c=1}^{K} N_{c} g_{c}+w \leq 0, j=1, \ldots, n \\
& \sum_{i=1}^{m} v_{i} \geq 1 \\
& \sum_{c=1}^{k} g_{c} \geq 1 \\
& \sum_{r=1}^{c} u_{r} \geq 1 \\
& \sum_{h=1}^{d} l_{h} \geq 1 \\
& \sum_{t=1}^{v} b_{t} \geq 1 \\
& \sum_{z=1}^{q} a_{z} \geq 1 \\
& \sum_{j=1}^{n} \lambda_{j}=1 \\
& \lambda_{j} \geq 0 \quad \theta_{p} \text { free }
\end{aligned}
$$

\subsection{Evaluation in MPI}

The MPI is measured to assess productivity growth based on the reference technology. The following two main topics are used in the calculation of MPI development:

- The first issue is that the number of productivity changes over the period.

- On the other hand, second is to decompose changes in productivity into what are generally denoted as a catching-up result or technical efficiency change (TEC) and a frontier shift result or technological change.

MPI measures the total factor productivity change of a DMU between two periods. The idea of productivity is typically denoted as labor productivity. This idea is related to TFP, defined as the product of efficiency change (catch-up) and technological change (frontier-shift). If TFP value is more than one, this specifies a progressive TFP growth from period $(t)$ to period $(t+1)$. However, a value of less than one yields a reduction in TFP development or performance relative to the preceding year. In fact:

Malmquist Productivity Index $(M P I)=T E C \times T C$

Eq. 14

The MPI can be stated through distance function(E) based on the two following equations applying the reflections at time $t$ and $t+1$ (Lee et al., 2011). 
The geometric mean of two MPI in equations (14) and (15) provides the equation (16):

$$
M P I_{I}^{G}=\left(M P I_{I}^{t}{ }_{M P I^{t+1}}\right)^{1 / 2}=\left[\left(\frac{E_{I}^{t}\left(x^{t+1}+y^{t+1}\right)}{E_{I}^{t}\left(x^{t}+y^{t}\right)}\right) \cdot\left(\frac{E^{t+1}{ }_{I}\left(x^{t+1}+y^{t+1}\right)}{E^{t+1}{ }_{I}\left(x^{t}+y^{t}\right)}\right)^{1 / 2}\right.
$$

Input oriented geometric mean of MPI can be disintegrated using the abovementioned input-oriented TC and input oriented TEC as follows:

$$
M P I_{I}^{G}=\left(T C_{I}\right)\left(T E C^{G}{ }_{I}\right)^{1 / 2}=\frac{E^{t+1}{ }_{I}\left(x^{t+1}+y^{t+1}\right)}{E_{I}^{t}\left(x^{t}+y^{t}\right)}\left[\left(\frac{E_{I}^{t}\left(x^{t}+y^{t}\right)}{E^{t+1}{ }_{I}\left(x^{t}+y^{t}\right)}\right) \cdot\left(\frac{E_{I}^{t}\left(x^{t+1}+y^{t+1}\right)}{E^{t+1}{ }_{I}\left(x^{t+1}+y^{t+1}\right)}\right)\right]^{1 / 2}
$$

MPI specified by equations (16) and (17) can be well-defined applying DEA, such as distance function. These are the elements of MPI which can be driven from the assessment of distance functions defined on frontier technology. Thus, the abovementioned MPI is the most common method between the numerous techniques that have been established to evaluate a production technology (Färe et al., 1994, Chen and Ali, 2004).

\subsection{Evaluation in Apriori algorithm in association rules}

After inserting the attributes and class by the WEKA software, the Apriori algorithm in association rules is applied. To select strong rules from the set of all possible rules, limitations on several methods of standing, and interest are used. The best-known restrictions are minimum commencements on support and confidence. Support is a sign of how recurrently the item set looks as if in the dataset. For example, the rule has the support of one in a data set, since it happens in $100 \%$ of all transactions (one out of one transaction). Confidence is a sign of how often the rule has been found to be precise. For example, the rule has the confidence of one in a data set, since, for $100 \%$ of the transactions, the rule is correct. If the rule had a lift of one, it would propose that the scene of being and the subsequent are independent of each other. When two procedures are independent, no rule can be drawn connecting those two events. If the lift is more than 1 , two procedures are independent of one another and make those rules hypothetically respected for forecasting the following in upcoming data sets. Under this condition that the lift is greater than one, the more the support and confidence of a rule in the Apriori algorithm, the higher it indicates a fixed outline in the dataset. If these procedures are relatively small, then any indiscretion would be less strong than it would be for rules with high confidence, great support, and high lift. After applying distinct data sets, association rules are assessed, and strong rules are extracted.

\subsection{Evaluation in classification algorithms in machine learning}

In this part three strong classification algorithms are introduced, and the basic calculation pf accuracy is presented:

K-Nearest Neighbor: K-nearest neighbors' algorithm (k-NN) is a non-parametric technique applied for classification and regression. In both classification and regression, the input contains the $\mathrm{k}$ closest training instances in the feature space. The output is a class member for classification and is an average of neighbor's value for regression.

Decision tree: Decision trees are generally implemented in operations research and decision analysis, to support classify an approach in order to reach a goal. In addition, it is a strong tool in machine learning. The flow chart structure of decision tree contains branch and leaf. Branch shows the result of the test and leaf displays the class label.

Naïve Bayes: Naïve Bayes classifiers are a part of simple "probabilistic classifiers" applying Bayes' formula with strong 
(naïve) individuality among the attributes. They are extremely accessible, demanding several constraints linear in the number of variables (features/predictors) in a learning programming.

4.8.4 Numeric accuracy calculation:

The efficiency of the classification algorithms based on the following accuracy formula was compared:

$\frac{\text { Truepositive }+ \text { Truenegative }}{\text { Truepositive }+ \text { Truenegative }+ \text { Falsepositive }+ \text { Falsenegative }}$

Thus, a true negative is an outcome where the model appropriately estimates the negative class. A false positive is an outcome where the model incorrectly estimates the positive class. And, a false negative is an outcome where the model inaccurately forecasts the negative class.

\subsection{Evaluation in Combining MPI and Machine learning algorithms}

Figure 3 shows the flowchart of proposed model

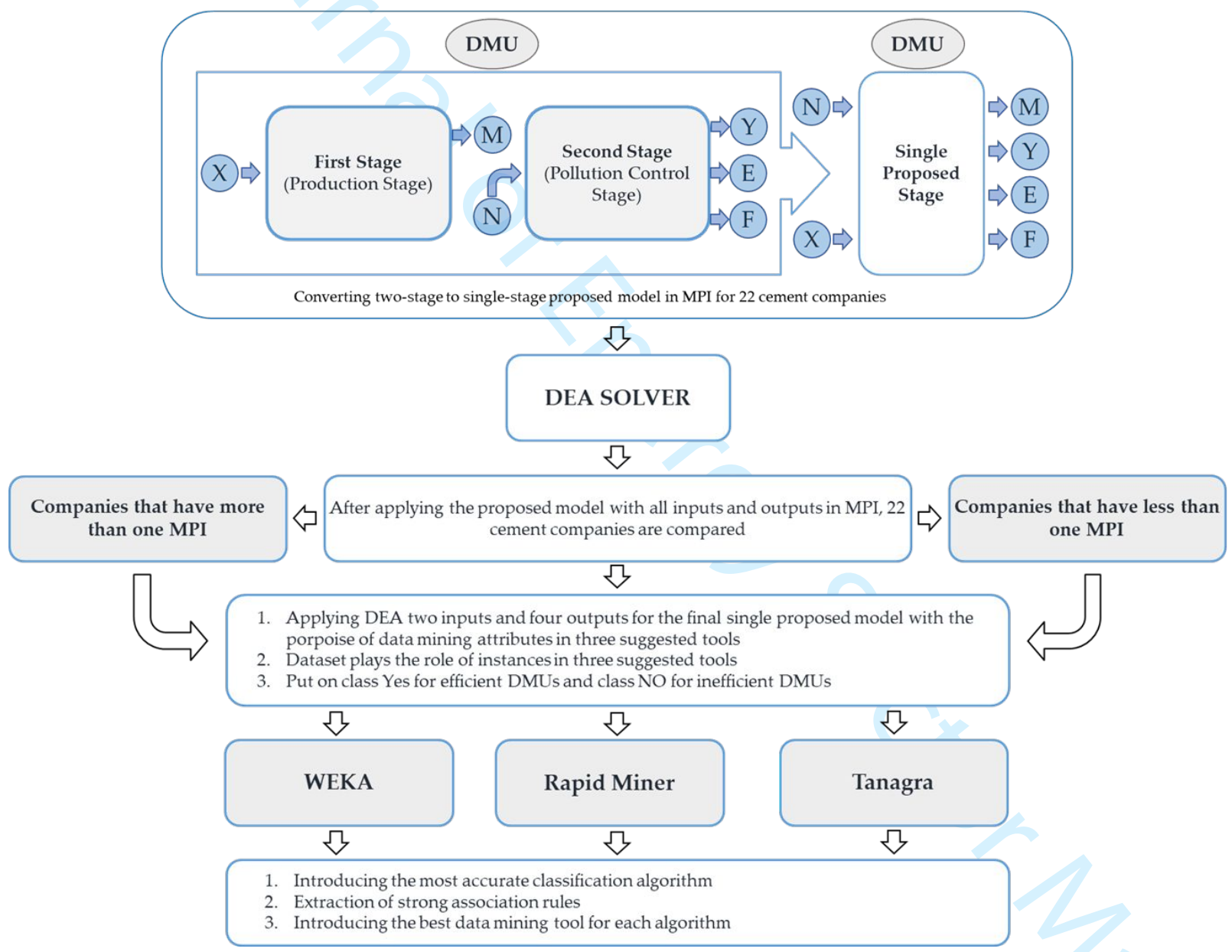

Fig. 3. Flowchart of proposed model

\section{Results and discussion}

The data covers in this study are five years from 2015 to 2019 for 22 local cement companies. The number of DMUs is $\mathrm{N}$ or 22, and the period is $\mathrm{T}$ or 5 . The average MPI for all cement companies during the years 2015-2019, based on the inputs and outputs, are given in Table 3 . 
Table 3. Productivity measurement results based on MPI-AM, MPI-BCC and MPI-CCR for 22 companies

\begin{tabular}{|c|c|c|c|c|c|c|}
\hline \multirow[b]{2}{*}{ Companies } & \multicolumn{2}{|l|}{1} & \multicolumn{2}{|l|}{2} & \multicolumn{2}{|l|}{3} \\
\hline & MPI-AM & Rank & MPI-BCC & Rank & MPI-CCR & Rank \\
\hline 1 & 1.098 & 5 & 1.094 & 5 & 1.090 & 5 \\
\hline 2 & 1.059 & 10 & 1.055 & 10 & 1.051 & 10 \\
\hline 3 & 1.133 & 4 & 1.129 & 4 & 1.125 & 4 \\
\hline 4 & 1.067 & 7 & 1.063 & 7 & 1.059 & 7 \\
\hline 5 & 0.898 & 21 & 0.894 & 21 & 0.890 & 21 \\
\hline 6 & 0.952 & 19 & 0.948 & 19 & 0.944 & 19 \\
\hline 7 & 1.061 & 8 & 1.057 & 8 & 1.053 & 8 \\
\hline 8 & 1.219 & 2 & 1.215 & 2 & 1.211 & 2 \\
\hline 9 & 1.051 & 11 & 1.046 & 11 & 1.043 & 11 \\
\hline 10 & 1.018 & 14 & 1.014 & 14 & 1.010 & 14 \\
\hline 11 & 0.874 & 22 & 0.870 & 22 & 0.866 & 22 \\
\hline 12 & 1.030 & 13 & 1.026 & 13 & 1.022 & 13 \\
\hline 13 & 1.058 & 9 & 1.054 & 9 & 1.050 & 9 \\
\hline 14 & 0.912 & 20 & 0.908 & 20 & 0.904 & 20 \\
\hline 15 & 1.015 & 16 & 1.011 & 16 & 1.007 & 16 \\
\hline 16 & 1.016 & 15 & 1.012 & 15 & 1.008 & 15 \\
\hline 17 & 1.431 & 1 & 1.427 & 1 & 1.423 & 1 \\
\hline 18 & 0.970 & 18 & 0.966 & 18 & 0.962 & 18 \\
\hline 19 & 1.033 & 12 & 1.029 & 12 & 1.025 & 12 \\
\hline 20 & 1.139 & 3 & 1.135 & 3 & 1.131 & 3 \\
\hline 21 & 1.071 & 6 & 1.067 & 6 & 1.063 & 6 \\
\hline 22 & 0.971 & 17 & 0.967 & 17 & 0.963 & 17 \\
\hline
\end{tabular}

The efficiency process for 22 companies are obtainable in Fig 4. Fig. 5, and Fig.6 and Table 3. In Fig 4. Fig. 5, and Fig.6 the horizontal axis characterizes the number of cement companies, and the vertical axis describes the average efficiency scores. As shown in Fig. 4, Fig. 5, Fig.6 and Table 3, the 17th company has the highest efficiency score, and the 11th company has the lowest efficiency score. The efficiency amount of 5th, 6th, 11th, 14th, 18th, and 22nd companies decreased over the five years.

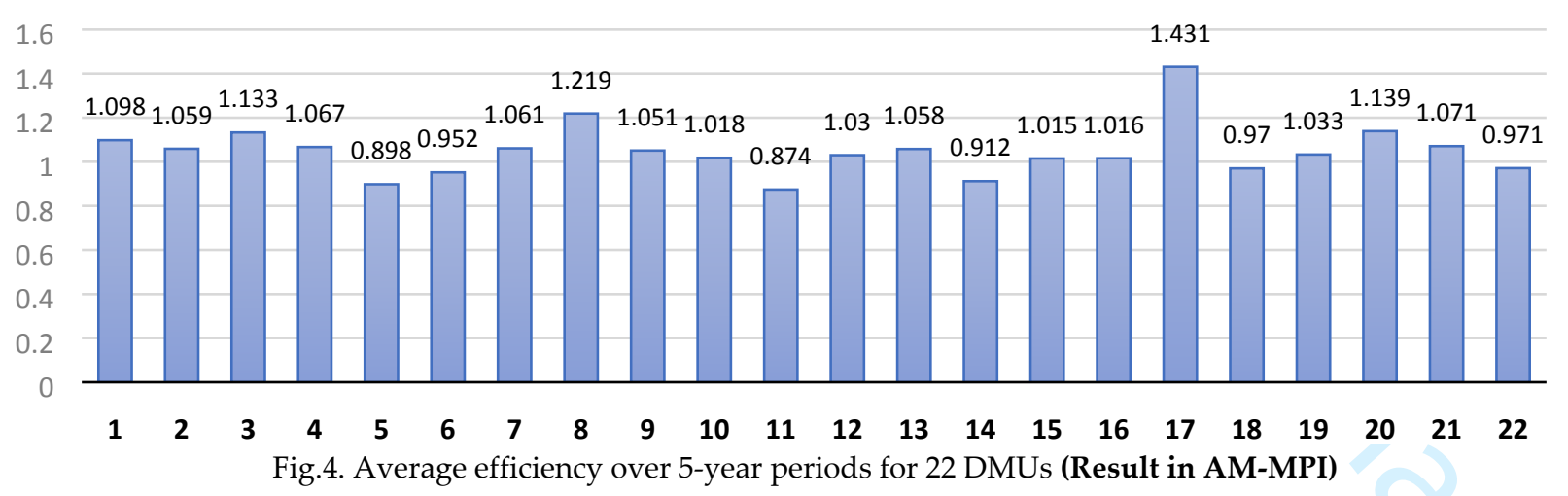



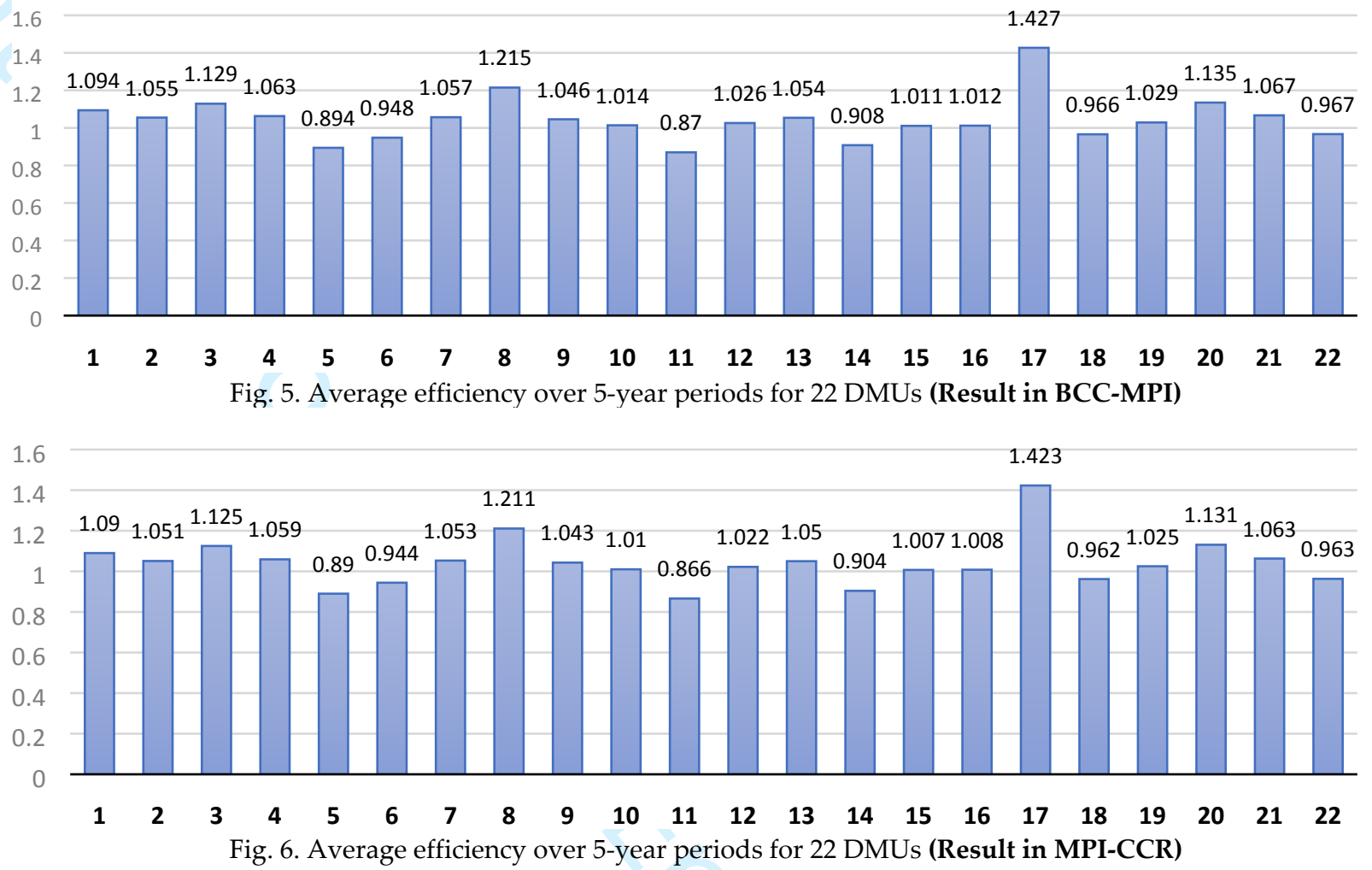

\subsection{Result in Apriori algorithm}

For the last part, three strong rules based on pseudocode have been proposed:

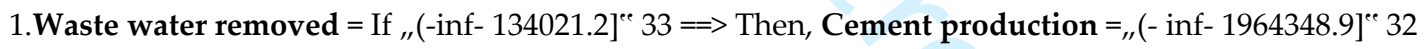

Based on the first strong rule if wastewater removed within the quantified range happens 33 times (33 out of 110), cement production within the quantified range will occur 32 times (32 out of 110).

2.Energy consumption= If „,(952946.9- 1549674.8]“ $26=\Rightarrow$ Then, Cement production =

Based on the second strong rule if energy consumption within the quantified range happens 26 times (26 out of 110), cement production within the quantified range will occur 24 times (24 out of 110).

3.Waste water removed in inefficient DMUs= If ,(-inf-134021.2] $20=>$ Then, Cement production $=$,(-inf$1964348.9]^{" C} 20$

Based on the third strong rule (sup:0.18, Conf: 1, lift: 1:43) in step C, if energy consumption in inefficient DMUs within the quantified range happens 20 times (20 out of 110), cement production within the quantified range will occur 20 times (20 out of 110).

\subsection{Result in classification algorithms}

Table 6. Accuracy of classification algorithms (all numbers are in percent)

\begin{tabular}{llll}
\hline Algorithms & WEKA & Tanagra & Rapid miner \\
\hline K-NN & 89.5122 & 93.0918 & $\mathbf{9 7 . 1 1 2 1}$ \\
Decision tree & $\mathbf{9 1 . 2 3 4 1}$ & 86.2467 & 80.1222 \\
Naïve Bayes & 79.2311 & $\mathbf{9 6 . 1 4 2 3}$ & 89.9087 \\
\hline
\end{tabular}

From above table WEKA tool predicts a lowest accuracy for Naive Bayes, however for the same algorithm Tanagra tool predicts the best accuracy when compared to WEKA and Rapid miner. In case of Decision tree evaluation, Rapid 
miner tool showed the lowest accuracy whereas WEKA tool estimated the best accuracy when compared to two other tools. For K-NN, Tanagra represented the highest accuracy. Finally, it can be concluded from table 6, each tool has a highest accuracy for three suggested strong classification algorithms.

\section{Conclusion}

The performance of the proposed approach provides us with a chance to recognize pattern recognition of the whole, combining DEA and data mining techniques during the selected period (five years from 2015 to-2019). Meanwhile, the cement industry is one of the foremost manufacturers of naturally harmful material using an undesirable by-product; specific stress is given to that pollution control investment or undesirable output while evaluating energy use efficiency. The significant concentration of the study is to respond to five preliminary questions. First, whether the conversion of the two-stage model to a novel single stage has any positive impact on Eco-efficiency? Secondly, among three proposed models (CCR, BCC, and AM models), which model has the highest average efficiency over 5-year periods for 22 DMUs? Thirdly, whether AM proposed model has any corroboration impact on Eco-efficiency? Fourthly, whether combining DEA and data mining have any strengthening influence on Eco-efficiency? and finally, whether comparison of three strong classification algorithms in three strong machine learning tools can be useful for future studies?

To answer the first question, this model is proposed to fix the efficiency of a two-stage process and prevent the dependency on various weights. Converting undesirable outputs, and desirable inputs to final desirable inputs in a single-stage model to minimize inputs as well as turning desirable outputs to final desirable outputs in the single stage model to maximize outputs to have a positive effect on the efficiency of the whole process. Decreasing pollutant material investment, as well as energy consumption (inputs of the single proposed model) and increasing waste material removed as well as cement production (outputs of the unique proposed model) have a positive influence on profits, and efficiency of cement companies. To answer the second question, the AM model has a more strengthening impact on Eco-efficiency compare with other models such as CCR and BCC input-oriented and output-oriented. To answer the third question, the AM model decreases the value of inputs and increases the value of outputs at the same time. To answer the fourth question, after applying previous steps in MPI, the data mining Apriori algorithm extracts the strongest rules and remove week rules. Finally, for the last and the fifth question, in order to implement the best tool and algorithm, a comparison of strong algorithms and tools will be beneficial for future studies. In conclusion, it is worth declaring the Limitations of this research. The most critical limitation is associated with the incomplete contemplation of undesirable output. The current study measured only pollution control investment as an undesirable output produced by the cement industry, and aforesaid unique methods have been proposed to decrease these undesirable outputs. However, other undesirable severe outputs also could have been combined into the analysis if reliable data were accessible. Containing these variables may affect the efficiency marks of this study. However, the general inference remains the same as the proposed combining method in this study, can put up several inputs and outputs. Along with the results obtained from efficiency analysis, the managers of the 17th cement company have the highest efficiency in cement production centers during the five years. They should try to have better efficiency in the future. Managers of other companies with less efficiency need to use specific data mining Apriori algorithm to enhance their efficiency. Consistent with the proposed approach, based on the geometric average, results, and predictions derived from the period in MPI can assist using a practical instrument for the general practitioner to compare the efficiency of uncertain cases and instruct effectively accordingly. 


\section{References}

AGARWAL, R. \& SRIKANT, R. Fast algorithms for mining association rules. Proc. of the 20th VLDB Conference, 1994. 487-499.

AGHAPOUR, A. H., YAZDANI, M., JOLAI, F. \& MOJTAHEDI, M. 2019. Capacity planning and reconfiguration for disaster-resilient health infrastructure. Journal of Building Engineering, 26, 100853.

AKBARZADEH BENGAR, H. \& SHAHMANSOURI, A. A. 2020. A new anchorage system for CFRP strips in externally strengthened RC continuous beams. Journal of Building Engineering, 30, 101230.

AKBARZADEH BENGAR, H., SHAHMANSOURI, A. A., AKKAS ZANGEBARI SABET, N., KABIRIFAR, K. \& W.Y. TAM, V. 2020. Impact of elevated temperatures on the structural performance of recycled rubber concrete: Experimental and mathematical modeling. Construction and Building Materials, 255, 119374.

ALMUTAIRI, H. \& ELHEDHLI, S. 2014. Modeling, analysis, and evaluation of a carbon tax policy based on the emission factor. Computers $\mathcal{E}$ Industrial Engineering, 77, 88-102.

ANGULO-MEZA, L., GONZÁLEZ-ARAYA, M., IRIARTE, A., REBOLLEDO-LEIVA, R. \& DE MELLO, J. C. S. 2019. A multiobjective DEA model to assess the eco-efficiency of agricultural practices within the CF+ DEA method. Computers and Electronics in Agriculture, 161, 151-161.

ARABI, B., DORAISAMY, S. M., EMROUZNEJAD, A. \& KHOSHROO, A. 2017. Eco-efficiency measurement and material balance principle: an application in power plants Malmquist Luenberger Index. Annals of Operations Research, 255, 221-239.

ARABI, B., MUNISAMY, S. \& EMROUZNEJAD, A. 2015. A new slacks-based measure of Malmquist-Luenberger index in the presence of undesirable outputs. Omega, 51, 29-37.

ARABI, B., MUNISAMY, S., EMROUZNEJAD, A. \& SHADMAN, F. 2014. Power industry restructuring and ecoefficiency changes: A new slacks-based model in Malmquist-Luenberger Index measurement. Energy policy, $68,132-145$.

ÁVALOS-RENDÓN, T. L., CHELALA, E. A. P., ESCOBEDO, C. J. M., FIGUEROA, I. A., LARA, V. H. \& PALACIOSROMERO, L. M. 2018. Synthesis of belite cements at low temperature from silica fume and natural commercial zeolite. Materials Science and Engineering: B, 229, 79-85.

AZADEH, A., AMALNICK, M., GHADERI, S. \& ASADZADEH, S. 2007. An integrated DEA PCA numerical taxonomy approach for energy efficiency assessment and consumption optimization in energy intensive manufacturing sectors. Energy policy, 35, 3792-3806.

AZADEH, A., SEIF, J., SHEIKHALISHAHI, M. \& YAZDANI, M. 2016. An integrated support vector regressionimperialist competitive algorithm for reliability estimation of a shearing machine. International Journal of Computer Integrated Manufacturing, 29, 16-24.

BALITSKIY, S., BILAN, Y., STRIELKOWSKI, W. \& ŠTREIMIKIENĖ, D. 2016. Energy efficiency and natural gas consumption in the context of economic development in the European Union. Renewable and Sustainable Energy Reviews, 55, 156-168.

BI, G.-B., SONG, W. \& WU, J. 2014. A clustering method for evaluating the environmental performance based on slacks-based measure. Computers \& Industrial Engineering, 72, 169-177.

BIAN, Y., HU, M., WANG, Y. \& XU, H. 2016. Energy efficiency analysis of the economic system in China during 1986-2012: a parallel slacks-based measure approach. Renewable and Sustainable Energy Reviews, 55, 990-998.

BOYD, G. A. \& PANG, J. X. 2000. Estimating the linkage between energy efficiency and productivity. Energy policy, 28, 289-296.

CHARNES, A., COOPER, W. W. \& RHODES, E. 1978. Measuring the efficiency of decision making units. European journal of operational research, 2, 429-444.

CHEN, Y. \& ALI, A. I. 2004. DEA Malmquist productivity measure: New insights with an application to computer industry. European journal of operational research, 159, 239-249.

CHEN, Y., COOK, W. D., LI, N. \& ZHU, J. 2009a. Additive efficiency decomposition in two-stage DEA. European journal of operational research, 196, 1170-1176.

CHEN, Y., LIANG, L. \& ZHU, J. 2009b. Equivalence in two-stage DEA approaches. European Journal of Operational Research, 193, 600-604. 
CHEN, Y., YAZDANI, M., MOJTAHEDI, M. \& NEWTON, S. 2019. The impact on neighbourhood residential property valuations of a newly proposed public transport project: The Sydney Northwest Metro case study. Transportation Research Interdisciplinary Perspectives, 3, 100070.

CHU, J., WU, J., ZHU, Q., AN, Q. \& XIONG, B. 2019. Analysis of China's regional eco-efficiency: A DEA two-stage network approach with equitable efficiency decomposition. Computational economics, 54, 1263-1285.

EMROUZNEJAD, A. \& YANG, G.-L. 2016a. CO2 emissions reduction of Chinese light manufacturing industries: A novel RAM-based global Malmquist-Luenberger productivity index. Energy Policy, 96, 397-410.

EMROUZNEJAD, A. \& YANG, G.-L. 2016b. A framework for measuring global Malmquist-Luenberger productivity index with CO2 emissions on Chinese manufacturing industries. Energy, 115, 840-856.

EMROUZNEJAD, A., YANG, G.-L. \& AMIN, G. R. 2019. A novel inverse DEA model with application to allocate the $\mathrm{CO} 2$ emissions quota to different regions in Chinese manufacturing industries. Journal of the Operational Research Society, 70, 1079-1090.

ENVIRONMENT, U., SCRIVENER, K. L., JOHN, V. M. \& GARTNER, E. M. 2018. Eco-efficient cements: Potential economically viable solutions for a low-CO2 cement-based materials industry. Cement and Concrete Research, 114, 2-26.

FÄRE, R., GROSSKOPF, S., NORRIS, M. \& ZHANG, Z. 1994. Productivity growth, technical progress, and efficiency change in industrialized countries. The American economic review, 66-83.

FATHOLLAHI-FARD, A. M., GOVINDAN, K., HAJIAGHAEI-KESHTELI, M. \& AHMADI, A. 2019. A green home health care supply chain: New modified simulated annealing algorithms. Journal of Cleaner Production, 240, 118200.

GHULAM, Y. \& JAFFRY, S. 2015. Efficiency and productivity of the cement industry: Pakistani experience of deregulation and privatisation. Omega, 54, 101-115.

GOLILARZ, N. A., GAO, H. \& DEMIREL, H. 2019. Satellite image de-noising with harris hawks meta heuristic optimization algorithm and improved adaptive generalized gaussian distribution threshold function. IEEE Access, 7, 57459-57468.

GOLILARZ, N. A., MIRMOZAFFARI, M., GASHTEROODKHANI, T. A., ALI, L., DOLATSARA, H. A., BOSKABADI, A. \& YAZDI, M. 2020. Optimized Wavelet-based Satellite Image De-noising with Multipopulation differential evolution-assisted Harris Hawks Optimization Algorithm. IEEE Access, 1-1.

GRAHAM, M. 2009. Developing a social perspective to farm performance analysis. Ecological Economics, 68, 23902398.

GRIGOROUDIS, E. \& PETRIDIS, K. 2019. Evaluation of National Environmental Efficiency Under Uncertainty Using Data Envelopment Analysis. Understanding Risks and Uncertainties in Energy and Climate Policy, 161.

HURLIMANN, A. C., WARREN-MYERS, G. \& BROWNE, G. R. 2019. Is the Australian construction industry prepared for climate change? Building and Environment, 153, 128-137.

JIANG, W., LIU, J. \& LIU, X. 2016. Impact of carbon quota allocation mechanism on emissions trading: An agentbased simulation. Sustainability, 8, 826.

JIN, M., SHI, X., EMROUZNEJAD, A. \& YANG, F. 2018. Determining the optimal carbon tax rate based on data envelopment analysis. Journal of Cleaner Production, 172, 900-908.

KABIRIFAR, K. \& MOJTAHEDI, M. 2019. The impact of Engineering, Procurement and Construction (EPC) phases on project performance: A case of large-scale residential construction project. Buildings, 9, 15.

KABIRIFAR, K., MOJTAHEDI, M., WANG, C. \& TAM, V. W. Y. 2020. Construction and demolition waste management contributing factors coupled with reduce, reuse, and recycle strategies for effective waste management: A review. Journal of Cleaner Production, 263, 121265.

KAO, C. \& HWANG, S.-N. 2008. Efficiency decomposition in two-stage data envelopment analysis: An application to non-life insurance companies in Taiwan. European journal of operational research, 185, 418-429.

KHALILI-DAMGHANI, K. \& SHAHMIR, Z. 2015. Uncertain network data envelopment analysis with undesirable outputs to evaluate the efficiency of electricity power production and distribution processes. Computers $\mathcal{E}$ Industrial Engineering, 88, 131-150.

KHALILI, S. M., BABAGOLZADEH, M., YAZDANI, M., SABERI, M. \& CHANG, E. A Bi-objective Model for Relief Supply Location in Post-Disaster Management. 2016 International Conference on Intelligent Networking and Collaborative Systems (INCoS), 2016. IEEE, 428-434. 
KHASREEN, M. M., BANFILL, P. F. \& MENZIES, G. F. 2009. Life-cycle assessment and the environmental impact of buildings: a review. Sustainability, 1, 674-701.

KHOSHROO, A., IZADIKHAH, M. \& EMROUZNEJAD, A. 2018. Improving energy efficiency considering reduction of $\mathrm{CO} 2$ emission of turnip production: A novel data envelopment analysis model with undesirable output approach. Journal of cleaner production, 187, 605-615.

KORHONEN, P. J. \& LUPTACIK, M. 2004. Eco-efficiency analysis of power plants: An extension of data envelopment analysis. European journal of operational research, 154, 437-446.

LEE, K.-R., LEEM, B., LEE, C. W. \& LEE, C. 2011. Malmquist Productivity Index using DEA frontier in Stata. Stata Journal, 2, 1-9.

LEE, P. \& PARK, Y.-J. 2017. Eco-efficiency evaluation considering environmental stringency. Sustainability, 9, 661.

LI, F., EMROUZNEJAD, A., YANG, G.-L. \& LI, Y. 2019. Carbon emission abatement quota allocation in Chinese manufacturing industries: An integrated cooperative game data envelopment analysis approach. Journal of the Operational Research Society, 1-30.

LI, K. \& LIN, B. 2016. Impact of energy conservation policies on the green productivity in China's manufacturing sector: Evidence from a three-stage DEA model. Applied Energy, 168, 351-363.

LIU, W., MENG, W., LI, X. \& ZHANG, D. 2010. DEA models with undesirable inputs and outputs. Annals of Operations Research, 173, 177-194.

LOTFI, F. H., ESHLAGHY, A. T., SALEH, H., NIKOOMARAM, H. \& SEYEDHOSEINI, S. 2012. A new two-stage data envelopment analysis (DEA) model for evaluating the branch performance of banks. African Journal of Business Management, 6, 7230-7241.

MAHMOUDI, P., MOHAMMADI, M. \& DANESHMAND, H. 2019a. Investigating the trend of average changes of annual temperatures in Iran. International Journal of Environmental Science and Technology, 16, 1079-1092.

MAHMOUDI, R., EMROUZNEJAD, A., KHOSROSHAHI, H., KHASHEI, M. \& RAJABI, P. 2019b. Performance evaluation of thermal power plants considering $\mathrm{CO} 2$ emission: A multistage PCA, clustering, game theory and data envelopment analysis. Journal of cleaner production, 223, 641-650.

METZ, B., DAVIDSON, O. \& DE CONINCK, H. 2005. Carbon dioxide capture and storage: special report of the intergovernmental panel on climate change, Cambridge University Press.

MIRMOZAFFARI, M. 2019. Eco-Efficiency Evaluation in Two-Stage Network Structure: Case Study: Cement Companies. Iranian Journal of Optimization, 11, 125-135.

MIRMOZAFFARI, M., YAZDANI, M., BOSKABADI, A., DOLATSARA, H. A., KABIRIFAR, K. \& GOLILARZ, N. A. 2020. A Novel Machine Learning Approach Combined with Optimization Models for Eco-efficiency Evaluation. Applied Sciences, 10, 5210.

MIRMOZAFFARI, M., AZEEM, G., BOSKABADI, A., ARANIZADEH, A., VATSHNAV, A., \& JOHN, J. 2020. A Novel Improved Data Envelopment Analysis Model Based on SBM and FDH Models. European Journal of Electrical Engineering and Computer Science, 4(3).

MOYA, D., TORRES, R. \& STEGEN, S. 2016. Analysis of the Ecuadorian energy audit practices: a review of energy efficiency promotion. Renewable and Sustainable Energy Reviews, 62, 289-296.

NAIK, A. \& SAMANT, L. 2016. Correlation review of classification algorithm using data mining tool: WEKA, Rapidminer, Tanagra, Orange and Knime. Procedia Computer Science, 85, 662-668.

NEMATZADEH, M., SHAHMANSOURI, A. A. \& FAKOOR, M. 2020. Post-fire compressive strength of recycled PET aggregate concrete reinforced with steel fibers: Optimization and prediction via RSM and GEP. Construction and Building Materials, 252, 119057.

ØDEGAARD, F. \& ROOS, P. 2014. Measuring the contribution of workers' health and psychosocial work-environment on production efficiency. Production and Operations Management, 23, 2191-2208.

OGGIONI, G., RICCARDI, R. \& TONINELLI, R. 2011. Eco-efficiency of the world cement industry: a data envelopment analysis. Energy Policy, 39, 2842-2854.

PACHECO-TORGAL, F., ABDOLLAHNEJAD, Z., CAMÕES, A., JAMSHIDI, M. \& DING, Y. 2012. Durability of alkali-activated binders: a clear advantage over Portland cement or an unproven issue? Construction and Building Materials, 30, 400-405.

QING, X.-X., XIAO, D. \& WANG, B. 2012. A real-time monitoring method of energy consumption based on data mining. Chongqing Daxue Xuebao(Ziran Kexue Ban), 35, 133-137.

RAKOTOMALALA, R. TANAGRA: un logiciel gratuit pour l'enseignement et la recherche. EGC, 2005. 697-702. 
SAMIMI, K., KAMALI-BERNARD, S., MAGHSOUDI, A. A., MAGHSOUDI, M. \& SIAD, H. 2017. Influence of pumice and zeolite on compressive strength, transport properties and resistance to chloride penetration of high strength self-compacting concretes. Construction and Building Materials, 151, 292-311.

SHAHMANSOURI, A., BENGAR, H. A. \& GHANBARI, S. 2020a. Experimental investigation and predictive modeling of compressive strength of pozzolanic geopolymer concrete using gene expression programming. Journal of Concrete Structures and Materials, 4.

SHAHMANSOURI, A. A., AKBARZADEH BENGAR, H. \& GHANBARI, S. 2020b. Compressive strength prediction of eco-efficient GGBS-based geopolymer concrete using GEP method. Journal of Building Engineering, 31, 101326.

SHAHMANSOURI, A. A., AKBARZADEH BENGAR, H. \& JAHANI, E. 2019. Predicting compressive strength and electrical resistivity of eco-friendly concrete containing natural zeolite via GEP algorithm. Construction and Building Materials, 229, 116883.

SHAHMANSOURI, A. A., YAZDANI, M., GHANBARI, S., AKBARZADEH BENGAR, H., JAFARI, A. \& FARROKH GHATTE, H. 2021. Artificial neural network model to predict the compressive strength of eco-friendly geopolymer concrete incorporating silica fume and natural zeolite. Journal of Cleaner Production, 279, 123697.

TAYLOR, M., TAM, C. \& GIELEN, D. 2006. Energy efficiency and CO2 emissions from the global cement industry. Korea, 50, 61.7.

TEKIN, I., GENCEL, O., GHOLAMPOUR, A., OREN, O. H., KOKSAL, F. \& OZBAKKALOGLU, T. 2020. Recycling zeolitic tuff and marble waste in the production of eco-friendly geopolymer concretes. Journal of Cleaner Production, 268, 122298.

WANG, W., KUANG, Y. \& HUANG, N. 2011. Study on the decomposition of factors affecting energy-related carbon emissions in Guangdong province, China. Energies, 4, 2249-2272.

WEI, Y.-M., LIAO, H. \& FAN, Y. 2007. An empirical analysis of energy efficiency in China's iron and steel sector. Energy, 32, 2262-2270.

YANG, H. \& POLLITT, M. 2010. The necessity of distinguishing weak and strong disposability among undesirable outputs in DEA: Environmental performance of Chinese coal-fired power plants. Energy Policy, 38, 44404444.

YANG, K.-H., SONG, J.-K. \& SONG, K.-I. 2013. Assessment of CO2 reduction of alkali-activated concrete. Journal of Cleaner Production, 39, 265-272.

YAZDANI, M., ALETI, A., KHALILI, S. M. \& JOLAI, F. 2017a. Optimizing the sum of maximum earliness and tardiness of the job shop scheduling problem. Computers $\mathcal{E}$ Industrial Engineering, 107, 12-24.

YAZDANI, M., BABAGOLZADEH, M., KAZEMITASH, N. \& SABERI, M. 2019. Reliability estimation using an integrated support vector regression-variable neighborhood search model. Journal of Industrial Information Integration, 15, 103-110.

YAZDANI, M. \& GHODSI, R. 2017. Invasive weed optimization algorithm for minimizing total weighted earliness and tardiness penalties on a single machine under aging effect. International Robotics and Automation Journal, $2,1-5$.

YAZDANI, M. \& JOLAI, F. 2013. A genetic algorithm with modified crossover operator for a two-agent scheduling problem. Journal of System Management, 1, -.

YAZDANI, M. \& JOLAI, F. 2016. Lion optimization algorithm (LOA): a nature-inspired metaheuristic algorithm. Journal of computational design and engineering, 3, 24-36.

YAZDANI, M., JOLAI, F., TALEGHANI, M. \& YAZDANI, R. 2018. A modified imperialist competitive algorithm for a two-agent single-machine scheduling under periodic maintenance consideration. International Journal of Operational Research, 32, 127-155.

YAZDANI, M., KABIRIFAR, K., FRIMPONG, B. E., SHARIATI, M., MIRMOZAFFARI, M. \& BOSKABADI, A. 2020 a. Improving Construction and Demolition Waste Collection Service in an Urban Area Using a Simheuristic Approach: A Case Study in Sydney, Australia. Journal of Cleaner Production, 124138.

YAZDANI, M., KHALILI, S. M., BABAGOLZADEH, M. \& JOLAI, F. 2017b. A single-machine scheduling problem with multiple unavailability constraints: A mathematical model and an enhanced variable neighborhood search approach. Journal of Computational Design and Engineering, 4, 46-59. 
YAZDANI, M., KHALILI, S. M. \& JOLAI, F. 2016. A parallel machine scheduling problem with two-agent and tool change activities: an efficient hybrid metaheuristic algorithm. International Journal of Computer Integrated Manufacturing.

YAZDANI, M., MOJTAHEDI, M. \& LOOSEMORE, M. 2020b. Enhancing evacuation response to extreme weather disasters using public transportation systems: a novel simheuristic approach. Journal of Computational Design and Engineering, 7, 195-210.

YU, S., WEI, Y.-M. \& WANG, K. 2014. Provincial allocation of carbon emission reduction targets in China: an approach based on improved fuzzy cluster and Shapley value decomposition. Energy policy, 66, 630-644.

ZENG, S. \& CHEN, J. 2016. Forecasting the allocation ratio of carbon emission allowance currency for 2020 and 2030 in China. Sustainability, 8, 650.

ZENG, S., HU, M. \& SU, B. 2016a. Research on investment efficiency and policy recommendations for the culture industry of China based on a three-stage DEA. Sustainability, 8, 324.

ZENG, S., XU, Y., WANG, L., CHEN, J. \& LI, Q. 2016b. Forecasting the allocative efficiency of carbon emission allowance financial assets in China at the provincial level in 2020. Energies, 9, 329.

ZHANG, B., BI, J., FAN, Z., YUAN, Z. \& GE, J. 2008. Eco-efficiency analysis of industrial system in China: A data envelopment analysis approach. Ecological economics, 68, 306-316.

ZHANG, N., ZHOU, P. \& KUNG, C.-C. 2015. Total-factor carbon emission performance of the Chinese transportation industry: A bootstrapped non-radial Malmquist index analysis. Renewable and Sustainable Energy Reviews, 41, 584-593.

ZHOU, P. \& ANG, B. W. 2008. Linear programming models for measuring economy-wide energy efficiency performance. Energy Policy, 36, 2911-2916. 